\title{
Clinical evaluation and management of neurogenic bowel after spinal cord injury
}

\author{
GI Correa*,1 and KP Rotter ${ }^{1}$ \\ ${ }^{1}$ Hospital del Trabajador de Santiago, Asociación Chilena de Seguridad, Chille
}

\begin{abstract}
Objectives: To assess the state of the neurological bowel in spinal cord injured (SCI) patients, design and apply a program for the comprehensive management of neurogenic bowel and evaluate outcome.

Setting: Out-patient in a Rehabilitation Service.

Subjects: Thirty-eight SCI patients, $12(32 \%)$ with complete lesions of more than 5 years duration.

Design: Observational, longitudinal and prospective. Pre and post intervention.

Method: Pre and post SCI intestinal function was evaluated clinically prior to beginning program. The presence of GI symptoms were studied. Laboratory work-up included colonic transit time (CTT), anorectal manometry and recto-colonoscopy. An intestinal program was designed, in order to achieve an effective and efficient evacuation in a predictable and socially acceptable time, to avoid short and long term complications and eliminate inadequate intestinal evacuation habits.

Outcome measures: Pre and post SCI difficulty in intestinal evacuation (DIE) was increased (from $2.6 \%$ to $26.3 \%$ ). The most frequent GI symptom was abdominal distention $(53 \%)$. Colonic inertia was present in $49 \%$ of CTT, internal anal sphincter pressure was normal or increased in $77 \%$ and rectoanal inhibitory reflex was present in $88 \%$. With the intestinal program, the incidence of DIE was reduced to $8.8 \%$, manual extraction (ME) was reduced from $53 \%$ to $37 \%$. Excellent and good results were obtained in $56 \%$ of the patients.

Conclusion: The proposed intestinal program is effective in the rehabilitation of SCI patients with neurogenic bowel. It is essential to initiate these physiological and safe procedures as soon as possible after sustaining the injury; this will lead to better results and to the elimination of inadequate intestinal maneuvering in the future.
\end{abstract}

Spinal Cord (2000) 38, 301-308

Keywords: chronic constipation; spinal cord injury; neuropathic bowel; bowel outcomes; bowel function; colonic transit

\section{Introduction}

Neurogenic bowel has a significant impact on the quality of life of spinal cord injured patients, causing morbidity and even death. ${ }^{1}$ The altered central or peripheral nervous system ${ }^{47}$ results in delayed gastric emptying, prolongation of intestinal transit time, and poor colonic motility. It is frequently manifested by post-prandial abdominal distention, decreased frequency of defecation and decreased water content in the stools resulting in increased stool hardness. ${ }^{3}$

Twenty-seven to $41 \%$ of patients with neurogenic bowel have chronic gastrointestinal problems that alter lifestyle and may require treatment. ${ }^{1,4,5}$ Nineteen to

*Correspondence: GI Correa, Hospital del Trabjador de Santiago, Asociación Chilena de Seguridad, Ramon Carnicer 185, Providencia, Santago, Chile
$23 \%$ of SCI patients required at least one hospitalization due to GI tract issues. ${ }^{5}$ The mortality for alimentary tract pathology is currently $10 \%{ }^{6}$

The effects of neurogenic bowel on life quality of SCI patients is significant. Fear of intestinal accidents, such as incontinence, frequently restrict patients from activities outside their home. ${ }^{2}$ Because chronic GI tract symptoms in SCI patients are infrequent within 5 years of the injury, this suggests that they may be preventable. $^{5}$

Constipation in these patients rarely responds to conservative treatment, patients may have to perform invasive, sometimes inadequate procedures in order to avoid fecal impactation and incontinence. This complicates their personal and social lives and increases physical and psychological dependence on others. $^{7}$ 
The objective of this study was to assess the state of the neurological bowel in patients with medullary or cauda equina injuries, to design and apply a program for the comprehensive management of neurogenic bowel and to evaluate the results of such a program.

\section{Materials and methods}

Forty-one patients with medullary or cauda equina injuries, (residents of Santiago, Metropolitan Region) were studied from May 1996 to July 1997. Three of these underwent colostomy at the beginning of the study, to prevent pressure ulcers, and none needed intestinal transit reconstruction. They, therefore, were excluded from the study. All patients were seen on an out-patient basis in the Rehabilitation Service of the Hospital del Trabajador de Santiago, Asociación Chilena de Seguridad. This is a private mutual company caring for patients who have had workplace accidents for the past 40 years.

The age, gender, level and type of spinal cord lesion, duration of lesion, psychological status, degree of independence in their intestinal management, defecation position, and use of medications likely to produce constipation as well as bowel augmentation cystoplasty were assessed. Pre and post spinal injury intestinal function was evaluated clinically prior to beginning the program (including assessment of intestinal habit, defecatory frequency, time of intestinal evacuation and stool consistency).

Difficult Intestinal Evacuation (DIE) $)^{2,27}$ is defined when two or more of the following are present: (a) Defecatory frequency of less than three times a week; ${ }^{7}$ (b) Hard stools. These cause urgency, difficult bowel evacuation, and sensation of incomplete evacuation; ${ }^{7,10}$ (c) Prolonged intestinal management time, more than 45 min., ${ }^{511-16}$ The term constipation is avoided because it is inexact. ${ }^{17}$ We evaluated the presence of the following gastrointestinal symptoms and complications: flatulence, post-prandial abdominal distention, ${ }^{5,18}$ abdominal pain, ${ }^{5}$ rectal bleeding and incontinence. ${ }^{4,13,14}$ These were marked in importance of their effect socially.

The laboratory work-up included colonic transit time (CTT), anorectal manometry and recto-colonoscopy. CTT was performed according to Karasick ${ }^{20}$ and Kannisto's ${ }^{3}$ modification of Arhan's technique. ${ }^{19}$ This technique is simple and inexpensive. . $^{3,7,8,19,21-29}$

The patients ingested 50 spherical, $1 \mathrm{~mm}$ radioopaque markers in a gelatin capsule. Throughout the study, the patients consumed their usual diet supplemented with water-soluble fiber. Abdominal $\mathrm{X}$-rays were taken immediately after ingestion of the capsule and every 5 days until fewer than $20 \%$ of the markers were seen radiographically. The markers were localized and counted, using the spine as a bony landmark, separating the right colon from left colon and the pelvic inlet that separates left colon from the rectosigmoid. ${ }^{19}$
The size of the colon was estimated radiographically immediately post ingestion of the markers by radiologists who were unaware of the patient's background. The test was rated as normal or abnormal according to the amount of markers that could be seen radiologically. If more than $20 \%$ were seen, it was considered abnormal. Retention of 10 or more markers in the right colon, left colon or rectosigmoid were defined as colonic inertia, hindgut dysfunction and outlet obstruction respectively. $8,20,22$ The finding of 10 or more markers gathered in more than one sector was considered a mixed pattern. Xrays taken every 5 days categorized the abnormal CTTs as follows: moderate, when more than 10 markers were seen until the tenth day; severe, when more than 10 markers were seen until the fifteenth day; and very severe when 10 or more markers were noted at 20 or more days.

Anorectal manometry was performed after a saline enema. A computerized on-line polygraph was used (Cynetics Medical), with a four channel open-tipped perfusion catheter with a distant balloon. Perfusion was performed with an Andorfer pump. The probe was introduced anally up to the rectal ampulla. The average highest pressure, which corresponds to the internal anal sphincter pressure (PIAS) was measured. Normal PIAS values for our laboratory range from 140 to $240 \mathrm{mmHg}$. ${ }^{229-31}$ The anorectal inhibitory reflex, that is the relaxation of the internal anal sphincter before rectal distention, was measured by insufflating the rectal balloon with 60,120 and $240 \mathrm{cc}$ of air and noting if relaxation of the sphincter was obtained. Before rectal insufflation the patient was asked whether he had defecatory sensation indicating presence or absence of the rectocortical reflex. Both reflexes are elicited at a rectal distention of up to $120 \mathrm{cc}$ of air.

The colon was prepared with oral polyethylene glycol before rectoscopy and colonoscopy. Inflammation, rectal ischemia, anorectal lesions and melanosis coli were noted if present. ${ }^{17,29}$ Pathological findings were photographed. A total of 35 CTT, 34 anorectal manometries and 36 recto-colonoscopies were performed on 38 patients.

The intestinal program was finally developed with the active participation of the patient; $;^{2,7,13,16,32}$ its goal was: (1) to achieve an effective and efficient evacuation in a predictable and socially acceptable period of time with an appropriate stool consistency and defecatory frequency; (2) to avoid fecal incontinence and other short and long term complications; (3) to eliminate inadequate intestinal evacuation habits. The rectoanal care that was used in our program was defined as a scheduled process of facilitated reflex defecation, with the establishment of a routine for stool evacuation, in a predictable and socially acceptable way. Various maneuvers were used gradually and sequentially, such as using a sitting position when defecating, applying pressure and massage to the abdomen, suppository use, and digital stimulation. ${ }^{2,33,47}$ 
A review of the literature indicates that evacuation by means of manual extraction, use of purge enemas and forbidden laxatives are considered to be inadequate practices of intestinal evacuation because of their inherent risk and possible complications. 2,3,9-14,19,20,23,24,29,32,33,35,39,41,46,47

Thirty-four of the 38 patients assessed were enrolled in our intestinal program. Four were excluded, one patient was in a terminal state for cancer, another died during the study period from non bowel related causes, another patient did not require treatment and one case refused changes in his current routine.

A program for intestinal management was designed according to the literature review. $1,2,7,11-14,17,32,34-44$ Figure 1 shows the program in a schematic form. The patient's intestinal function, symptoms and complications were evaluated monthly. They were educated regarding inadequate practices of evacuation, and medications were changed where necessary. After 6 months on the Program, and having achieved stability in their intestinal management, the patient's intestinal function, symptoms and possible complications as well as compliance were reevaluated. Patient compliance was defined as patient's adherence to the medical regimen and prescribed drugs.

Global results of the program were classified as Excellent: patient's defecatory habits were regular, with an acceptable intestinal function (three or more times a week with stools of normal consistency, 'like a snake', smooth and soft, with an evacuation time less than $45 \mathrm{~min}$ ); Good: patients did not achieve a regular defecatory habit, with acceptable intestinal function, defecatory frequency three or more times a week, formed normal stools, evacuation time less than
$45 \mathrm{~min}$, and, patients did not carry out inadequate practices of intestinal management; Fair: Patients with or without a regular defecatory habit, acceptable intestinal function, defecatory frequency sometimes $>$ three times weekly, evacuation of hard stools and/or evacuation time more than $45 \mathrm{~min}$. Patients occasionally performed inadequate intestinal management procedures, eg manual removal and; Poor: with or without regular defecatory habit, acceptable intestinal function or DIE. Patients performed frequent inadequate intestinal management procedures.

Patient compliance was essential in the achievement of our goals. Informed consent was obtained from each patient after he/she was fully informed about the study and procedures, confidentiality of the information, and that there was no risk to their health. Enrolment to the program as well as undergoing the various tests was voluntary. Two patients refused one of the three procedures used in the study and one other patient refused participation in the program.

\section{Statistical analysis}

Normal paired bilateral tests corrected for continuity and paired Chi square for pre and post DIE evaluation of the program ( $\mathrm{z}$ paired); paired Chi square or McNemar with correction of continuity was applied. McNemar ( $\chi^{2}$ paired) or exact binomial probability test (EB) were applied for comparison of paired variable proportions, depending on sample size. For comparison of mean paired variables, such as defecatory frequency pre and post program application, the $t$ bilateral paired Student test was applied ( $t$ paired) with

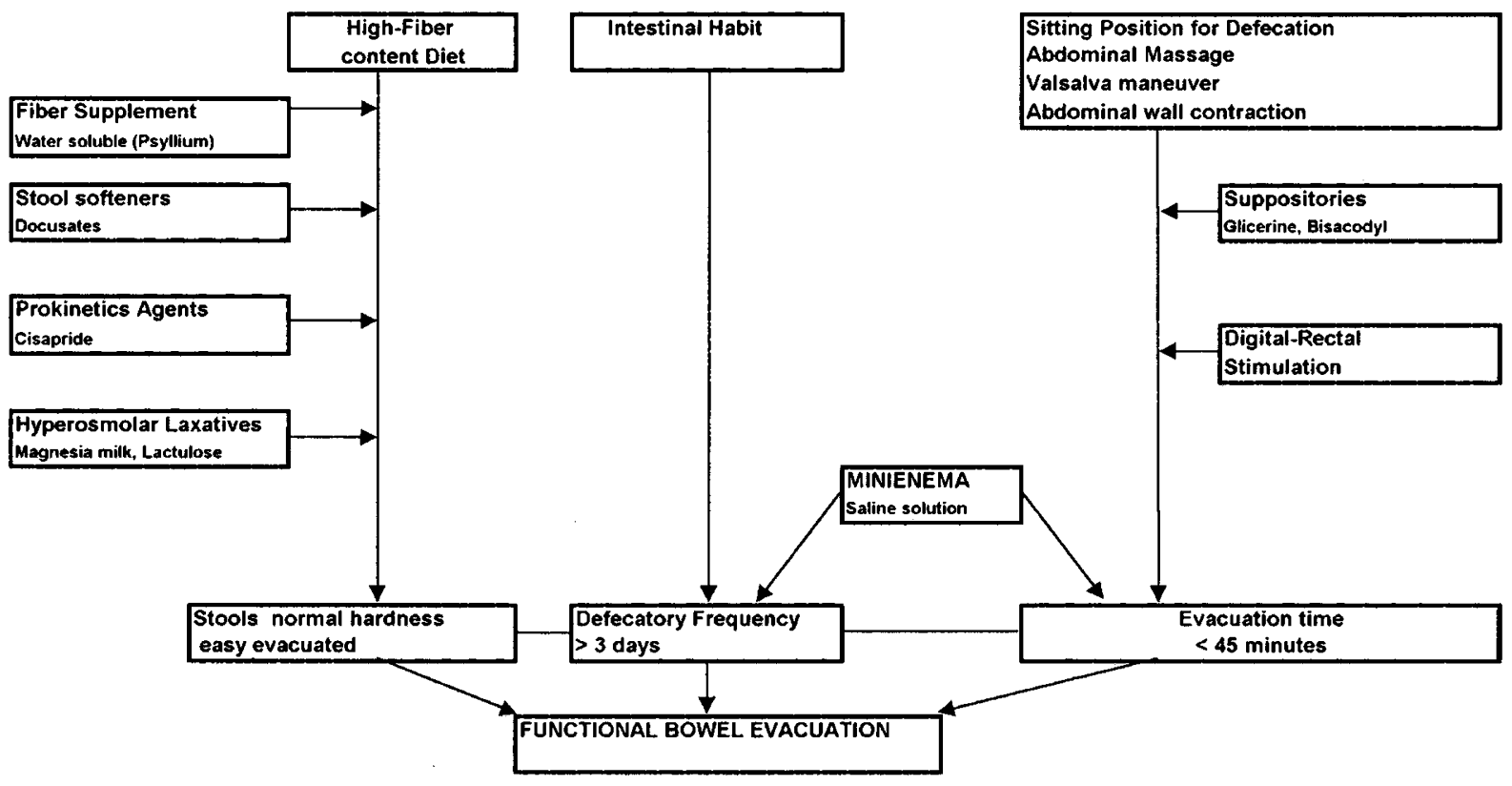

Figure 1 Intestinal program for spinal cord and equina cauda injured patients 
or without logarithmic correction, or Wilcoxon's sign range test depending on size and SD of samples. For comparison of mean variables in two samples, such as age and duration of SCI, with and without DIE, the $t$ bilateral Student test was applied $(t)$, with or without logarithmic correction, or Wilcoxon's range addition test, depending on size and SD of samples.

\section{Results}

We studied 38 patients: 34 men, four women; ages 43 $( \pm 12.1)$ years, ranging from 19 to 71 years of age. Twenty-one patients had complete medullary lesions (CML) (55.3\%), 10 had incomplete medullary lesions (IML) $(26.3 \%)$ and seven had medullary cone syndrome and cauda equina (CC) $(18.4 \%)$. Two of the CML had cervical (9.5); six had high thoracic $(28.6 \%)$ and 13 had low thoracic levels of injury $(61.9 \%)$.

IMLs were composed of five central medullar syndromes $(50 \%)$; one posterior chord syndrome $(10 \%)$, three ASIA B lesions $(30 \%)$ and one ASIA $\mathrm{D}(10 \%)$. Time from injury to beginning of study was $6( \pm 3.7)$ years ranging from 5 months to 16 years. In 22 patients $(58 \%)$ the SCI had been sustained more than 5 years previous to entering the study. Twelve patients $(32 \%)$ had complete lesions for more than 5 years previous to entering the study. Moderate to severe psychological involvement was present in seven patients $(18.4 \%)$ related to concurrent encephalic lesion. Twenty-eight patients $(73.6 \%)$ were in wheel chairs, $10(26.3 \%)$ ambulated with or without orthosis. Independent intestinal management was present in 28 patients, 10 patients required help from another person $(26.3 \%)$. Nine patients defecated in bed, 29 managed their bowels by sitting on special WC chairs or in the toilet.

Fifteen patients $(39.5 \%)$ were on anticholinergic, amytriptiline and/or oxybutinine medication which could produce constipation. Bowel augmentation cystoplasty was performed in nine patients $(23.7 \%)$ on average 5.8 years before entering the study. When comparing pre and post lesion intestinal function at the onset of the study, a decreased defecatory frequency was noted which ranged from $8.2( \pm 3.8)$ to $5.2( \pm 3.6)$ times a week with an increased evacuation time which ranged from $9.7( \pm 0.9)$ to $24.1( \pm 23.9) \mathrm{min}$ respectively, both differences were statistically significant $(P<0.001 ; t$ paired). DIE increased significantly post lesion from $2.6 \%$ to $26.3 \%, P=0.031$ (EB).

Regular intestinal schedule (or habit) was present in 21 patients $(55.3 \%)$, with no differences in the pre and post injury condition before starting with the program.

Issues probably arising from post-medullar lesion DIE are related to poor intestinal habits and the ingestion of potentially constipating medication (Table 1). At the onset of the study, 36 patients $(94.7 \%)$ had GI tract symptoms, the most frequent being abdominal distention (52.6\%) (Table 2). Symptoms were present more than once a week in 14 patients $(36.8 \%)$, leading to severe social problems in three patients $(7.9 \%)$, two of who had frequent fecal incontinence. Simple abdominal X-rays revealed colonic dilatation which was moderate in 13 patients $(37 \%)$ and severe in eight $(21 \%)$.

The most common CTT pattern was colonic inertia, present in 17 patients $(48.6 \%)$ with severely decreased marker elimination time in 10 patients $(28.6 \%)$ (Tables 3 and 4 ). No significant differences were noted when analyzing distribution patterns according to lesion type. PIAS in anorectal manometry was $91.5( \pm 35) \mathrm{mmHg}$ (36 at 206). No different levels of pressure were detected according to type of lesion. PIAS was normal in 22 patients $(64.7 \%)$, increased in four $(11.8 \%)$ and decreased in eight.

Table 2 Gastrointestinal symptoms before Intestinal Program

\begin{tabular}{lcc}
\hline & $\mathrm{n}$ & $\%$ \\
\hline Abdominal distention & 20 & 52.6 \\
Abdominal pain & 11 & 28.9 \\
Flatulence & 19 & 50.0 \\
Rectal bleeding & 15 & 39.5 \\
Fecal incontinence & 19 & 50.0 \\
\hline
\end{tabular}

Table 1 Issues related to Difficult Intestinal Evacuation

\begin{tabular}{|c|c|c|c|c|c|}
\hline & \multicolumn{2}{|c|}{$\begin{array}{c}\text { With DIE } \\
\mathrm{n}=10\end{array}$} & \multicolumn{2}{|c|}{$\begin{array}{l}\text { Without DIE } \\
\mathrm{n}=21\end{array}$} & \\
\hline & $\mathrm{n}$ & $\%$ & $\mathrm{n}$ & $\%$ & \\
\hline Complete injury & 5 & 50 & 12 & 27.1 & nss \\
\hline Duration SCI & 5 & 50 & 16 & 76.2 & nss \\
\hline Moderate/severe psychological deterioration & 3 & 30 & 2 & 9.5 & nss \\
\hline Functional dependence & 7 & 70 & 9 & 42.9 & nss \\
\hline Bowel care dependence & 3 & 30 & 5 & 23.8 & nss \\
\hline Bowel habit & 1 & 10 & 13 & 61.9 & $\operatorname{ss}(\mathrm{z}) P=0.01$ \\
\hline Defecate in bed & 3 & 30 & 5 & 23.8 & nss \\
\hline Previous inadequate practices & 8 & 80 & 14 & 66.7 & nss \\
\hline Using potentially constipating medication & 8 & 80 & 4 & 19.0 & ss (ET) $P=0.004$ \\
\hline Bowel augmentation cystoplasty & 1 & 10 & 6 & 28.6 & nss \\
\hline
\end{tabular}


Table 3 Pattern of distribution of radio-opaque markers in CTT

\begin{tabular}{lcc}
\hline & $\mathrm{n}$ & $\%$ \\
\hline Colonic inertia & 17 & 48.3 \\
Hindgut dysfunction & 1 & 2.9 \\
Outlet obstruction & 1 & 2.9 \\
Mixed & 14 & 40.0 \\
Normal & 2 & 5.7 \\
Total & 35 & 100.0 \\
\hline
\end{tabular}

Table 4 Elimination time of radio-opaque markers in CTT

\begin{tabular}{lcc}
\hline Time (days) & $\mathrm{n}$ & $\%$ \\
\hline 5 & 2 & 5.7 \\
10 & 13 & 37.1 \\
15 & 5 & 14.3 \\
20 & 5 & 14.3 \\
$>20$ & 10 & 28.6 \\
Total & 35 & 100.0 \\
\hline
\end{tabular}

Voluntary Control Pressure (PVC) was present in six of the nine IML patients and 6/7 cone and cauda equina lesions $(85.7 \%)$ reaching values of $43.7( \pm 36.0)$ $\mathrm{mmHg}$, much lower than normal values. There were no statistical differences between both groups. The inhibitory anorectal reflex was present in 30 patients $(88.2 \%)$ with no significant differences according to the type of lesion. Recto-cortical reflex was present only in IML and cauda equina lesions in 10/16 patients $(62.5 \%)$.

Sixteen $(44.4 \%)$ anorectal lesions were seen in 36 rectoscopies. The most frequent was hemorrhoids, 13 patients $(36 \%)$ which were symptomatic in eight patients $(61.5 \%)$ (Table 5). A transverse colon hemangioma was present in one IML patient. The program was applied on 34 patients for $10.4( \pm 1.5)$ months, ranging from 6-13 months. More than one type of treatment was used in 30 patients $(88.2 \%)$.

Water soluble fiber supplementation, psyllium mucilage was given to 30 patients $(88.2 \%)$; three patients $(10 \%)$ did not tolerate it because of abdominal distention, flatulence and acidity, and three other patients stopped it spontaneously. On ending the program, 24 patients $(70.6 \%)$ were on fiber supplement. The average dose was $8.9 \mathrm{~g} /$ day ranging from 5.8 to $17.4 \mathrm{~g} /$ day.

Glycerin suppositories were used in 25 patients $(73.5 \%)$. Four patients had difficulty placing them and four did not like the administration route. At the end of the program, 16 patients $(47.1 \%)$ were using suppositories, 10 used $1-3$ per application.

Anal stimulation was used by 17 patients (50\%); 12 patients $(35.3 \%)$ continued with this method until ending the program.
Table 5 Recto-anal lesions seen on rectoscopy

\begin{tabular}{lcc}
\hline & $\mathrm{n}$ & $\%$ \\
\hline Hemorrhoids & 13 & 36.1 \\
Rectal polyps & 3 & 8.3 \\
Chronic papilitis & 2 & 5.6 \\
Anusitis & 1 & 2.8 \\
Proctitis & 1 & 2.8 \\
Chronic anal fissure & 1 & 2.8 \\
\hline
\end{tabular}

Sodium Docusate was used in 15 patients $(44.1 \%)$, one of whom was intolerant to its use $(6.7 \%)$. Eight patients $(53.3 \%)$ stopped medication by themselves due to poor results and in two patients because of poor results its prescription was ended. On ending the program, four patients $(26.7 \%)$ were on Docusate at average doses of $150 \mathrm{mg} /$ day ranging from $100-$ $200 \mathrm{mg} /$ day.

Cisapride, $30 \mathrm{mg}$ /day was used in 22 patients $(64.7 \%)$. Four manifested intolerance $(17 \%)$ two of whom had abdominal distention, one had nausea, another developed headache, flatulence and abdominal distention.

CTT was performed 5 months post cisapride ingestion in 16 patients $(72.7 \%)$ and no significant changes were seen when compared to initial scans. Cisapride was stopped in the 12 patients $(54.5 \%)$ that had no pre and post medication changes in their CTT. Mini-enemas were used as part of the program when there was no defecation with usual maneuvers after 3 days. In two medullar injured patients this was used sporadically.

At the end of the study, 32 patients in all (94.1\%) had acquired appropriate bowel management habits. Ten of these $(29 \%)$ previously had no adequate bowel management habits. An important objective of the program was to eliminate inadequate habits of evacuation, such as ME, use of evacuating and saline enemas, stimulants and other forbidden laxatives. Before program application $67.6 \%$ of the patients were using inadequate maneuvers, the most common being ME (18 patients $(52.9 \%)), 19 \mathrm{CML}$ patients were using this procedure pre program, eight of these $(42.1 \%)$ in a daily fashion.

At the end of the study, inadequate habits were reduced to $23.5 \%$ of all patients. ME in CML was reduced to seven patients $(36.6 \%)$, two of which $(10.5 \%)$ performed it every day. Both reductions were statistically significant, $P=0.007$ and $P=0.03$ (EB) respectively (Table 6). Compliance to the program was good in 11 patients $(32.4 \%)$, fair in $18(52.9 \%)$ and poor in five $(14.7 \%)$.

DIE decreased significantly as well as stool consistency and evacuation time (Table 7). The number of defecations per week increased to $6.1( \pm 3.5), \quad P=0.02(t \log 10)$. GI tract symptoms persisted in 20 patients $(58.8 \%)$, flatulence being the most prevalent $(35.3 \%)$. The main feature was 
Table 6 Inadequate practices before and after program

\begin{tabular}{|c|c|c|c|c|c|}
\hline \multirow[b]{2}{*}{ Practice } & \multicolumn{2}{|c|}{ Before program } & \multicolumn{2}{|c|}{ After program } & \\
\hline & $\mathrm{n}$ & $\%$ & $\mathrm{n}$ & $\%$ & \\
\hline Manual evacuation & 18 & 52.9 & 7 & 20.6 & ss (z) $P=0.001$ \\
\hline Evacuating enema & 4 & 11.8 & 1 & 2.9 & nss \\
\hline Forbidden laxatives & 8 & 23.5 & 0 & 0.0 & ss (EB) $P=0.003$ \\
\hline Total & 23 & 67.6 & 8 & 23.5 & ss (z) $P=0.0002$ \\
\hline
\end{tabular}

(34 patients completing program)

Table 7 Difficult Intestinal Evacuation before and after program

\begin{tabular}{|c|c|c|c|c|c|}
\hline & \multicolumn{2}{|c|}{ Before program } & \multicolumn{2}{|c|}{ After program } & \\
\hline & $\mathrm{n}$ & $\%$ & $\mathrm{n}$ & $\%$ & \\
\hline Defecatory frequency $<3$ days & 4 & 11.8 & 1 & 2.9 & nss \\
\hline Hard stools & 9 & 26.5 & 1 & 2.9 & ss (EB) $P=0.004$ \\
\hline Evacuation time $>45 \min$ & 9 & 26.5 & 4 & 11.8 & ss (EB) $P=0.015$ \\
\hline Total & 9 & 26.5 & 3 & 23.5 & ss (EB) $P=0.03$ \\
\hline
\end{tabular}

(34 patients completing program)

Table 8 Gastrointestinal symptoms before and after programs

\begin{tabular}{|c|c|c|c|c|c|}
\hline & & & & & \\
\hline & $\mathrm{n}$ & $\%$ & $\mathrm{n}$ & $\%$ & \\
\hline Abdominal distention & 17 & 50.0 & 8 & 23.5 & ss (z) $P=0.008$ \\
\hline Abdominal pain & 10 & 29.4 & 5 & 14.7 & nss \\
\hline Flatulence & 16 & 27.1 & 12 & 35.3 & nss \\
\hline Rectal bleeding & 15 & 44.1 & 3 & 8.8 & ss (z) $P=0.001$ \\
\hline Fecal incontinence & 17 & 50.0 & 6 & 17.6 & ss (z) $P=0.001$ \\
\hline
\end{tabular}

(34 patients completing program)

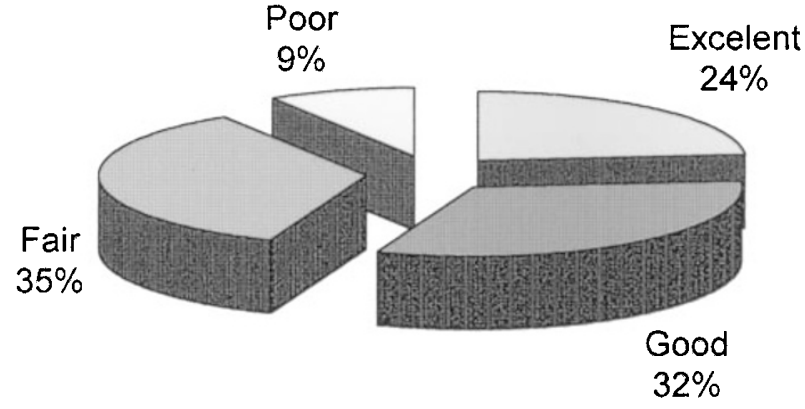

Figure 2 Global results of intestinal program in spinal cord and cauda equina patients

significant decrease in rectal bleeding, abdominal distention and fecal incontinence (Table 8).

Symptoms were persistent more than once a week in five patients $(14.7 \%), P=0.007(\mathrm{BE})$. Interference with social interaction was eliminated in all patients. Global results were Excellent and Good in 56\% (Figure 2). No differences according to type or time of lesion were noted.

\section{Discussion}

Our study population comprised mostly complete medullary injured patients $(55.3 \%)$, with more than
5 years duration previous to entering this study $(57.9 \%)$. According to the literature, this type of patient is under greater risk of intestinal complications. ${ }^{45}$

After sustaining a medullary lesion, there is a clear decrease in defecatory frequency, increased evacuation time and the stools are harder, increasing DIE from $2.6 \%$ to $26.3 \%$. These findings are in agreement with the literature. Glickman ${ }^{13}$ noted increased constipation going from $5 \%$ before injury to $30 \%$ post lesion. Since there is a loss of conscious defecation, it is important to introduce a predictable stool elimination routine to avoid colonic over-distention. ${ }^{2,7,32}$ Ninety per cent of the patients with DIE in this study did not have a defecatory routine or habit, while $38 \%$ did not have DIE. With the use of the program, $10 \%$ of the patients acquired intestinal habit. Potentially constipating drugs were used by $39.5 \%$ of patients for depression or vesical hyperreflexia, leading to increased DIE. These drugs impair intestinal motility and dry the stools. 2,34,46 Their use must be avoided in these patients or other treatment modalities must be applied.

The most frequent GI tract symptom was abdominal distention, $52.6 \%$ of the patients. This is in agreement with Stone $^{5}$ who reported a $43 \%$ prevalence.

Colonic transit time showed mostly an inertia pattern $(48.6 \%)$ which was very severe in $29 \%$ of the 
patients. These results are important for treatment concerns.

The internal and sphincter pressure was normal or increased in $87 \%$ of the patients, assuring continence. Nonetheless, there was occasional fecal incontinence in $50 \%$, which decreased with the program to $17 \%$. It is probable that in these patients incontinence was due to inadequate intestinal management and to the use of stimulating laxatives. 5,17

The inhibitory anorectal reflex was present in $88 \%$ of the patients, even in cervical medullary injured patients who used evacuating enema as the only procedure for years. This finding supports the fact that changing to a more physiological procedure is beneficial, even for these patients. The prevalence of hemorrhoids was $36 \%$, lower than the $74 \%$ reported by Stone. More than one treatment modality was used in $67.6 \%$ of the patients, less than Glickman's reported $95 \%$. $^{13}$

The use of cisapride is currently debatable. Although some series have reported its value in this type of patient, other controlled studies have demonstrated no effect on oroanal transit time, as was seen in our study. $2,7,12,34,35,37-42,46,47$

Manual extraction is a dangerous and bad habit since it may damage the anorectal mucosa and the anal sphincter in this anesthetized area. Reducing this practice is considered a great success. After ending the treatment period, $37 \%$ of CML patients performed ME and only $10 \%$ used this method daily, much less than the $26 \%$ reported by Glickman and Levi's $64 \% .^{4,13}$ The program significantly reduced DIE incidence from $26.5 \%$ to $8.8 \%$, as well as the GI tract symptoms and the social impact thereupon.

The global outcome of the program was excellent and good in $56 \%$ of the patients, nonetheless, results were bad in three patients $(8.8 \%)$ who continued $\mathrm{ME}$ or did not comply with the program. It is essential to initiate physiological and safe procedures such as those described in our program as soon as possible after sustaining the injury: this will lead to better results and to the elimination of inadequate intestinal management maneuvers in the future.

The colon is a fertile new field of learning for research, for innovation and for an improved quality of life after suffering a medullar lesion. ${ }^{2}$

\section{Acknowledgements}

To José Finkelstein, MD, Head of the Rehabilitation Service, Hospital del Trabajador de Santiago, for his valuable help in this research. To Enrique Bosh, MD, Patricio Azócar, MD (Radiologists) and Medical Technician $\mathrm{Mr}$ Guillermo Rojo who performed the Colonic Transit Times on our patients; to Mrs Lenka Parada, RN and special thanks to Mrs Valeria Rojas, our secretary. This research has been supported by the Comite de Investigación Cientifica de la Asociación Chilena de Seguridad, OTI 0662-3.

\section{References}

1 Banwell J, Creasey G, Aggarwall A, Mortimer T. Management of the neurogenic bowel in patients with spinal cord injury. Urol Clin N Am 1993; 20: 517-526.

2 Stiens SA, Bergman SB, Goetz LL. Neurogenic bowel dysfunction after spinal cord injury: clinical evaluation and rehabilitative management. Arch Phys Med Rehabil 1997; 78: 86-102.

3 Kannisto M, Rintala R. Bowel function in adults who have sustained spinal cord injury in childhood. Paraplegia 1995; 33: $701-703$

4 Levi R, Hulting C, Nash M, Seger A. The Stockholm spinal cord injury study. 1. Medical problems in a regional SCI population. Paraplegia 1995; 33: 308-315.

5 Stone JM, Nino-Murcia M, Wolfe VA, Perkash I. Chronic gastrointestinal problems in spinal cord injury patients: a prospective analysis. Am J Gastroenterol 1990; 85: 1114-1119.

6 Gore RM, Mintzer RA, Calenoff L. Gastrointestinal complications of spinal cord injury. Spine 1981; 6: $538-544$

7 Badiali D et al. Sequential treatment of chronic constipation in paraplegic subjects. Spinal Cord 1997; 35: 116-120.

8 Karlbom U, Pahlman L, Nilsson S, Graf W. Relationships between defecographic findings, rectal emptying, and colonic transit time in constipated patients. Gut 1995; 6: 907-912.

9 Talley NJ et al. Constipation in an elderly community: a study of prevalence and potential risk factors. Am J Gastroenterol 1996; 91: $19-25$.

10 Heaton KW et al. Defecation frequency and timing, and stool form in the general population: a prospective study. Gut 1992; 33: $818-824$

11 Cameron K, Nyulasi Y, Collier G, Brown D. Assessment of the effect of increased dietary fibre intake on bowel function in patients with spinal cord injury. Spinal Cord 1996; 34: 277-283.

12 Geders JM, Gaing A, Bauman WA, Korsten MA. The effect of cisapride on segmental colonic transit time in patients with spinal cord injury. Am J Gastroenterol 1995; 90: 285-289.

13 Glickman S, Kamm MA. Bowel dysfunction in spinal cord-injury patients. Lancet 1996; 347: $1651-1653$.

14 King JC, Currie DM, Wright E. Bowel training in Spina Bifida: Importance of education patient compliance, age, and anal reflexes. Arch Phys Med Rehabil 1994; 75: 243-247.

15 Stiens SA. Reduction in bowel program duration with polyethylene glycol based bisacodil suppositories. Arch Phys Med Rehabil 1995; 76: 674-677.

16 Weingarden SI. The gastrointestinal system and spinal cord injury. Clinics of Physical Medicine and Rehabilitation 1992; 3: $765-781$.

17 Lisenmeyer TA, Stone JM. Chap 36: Neurogenic Bladder and Bowel Dysfunction. In: Delisa J, Gans B (eds), Rehabilitation Medicine, Principles and Practice, 2nd edn. JB Lippincott: Philadelphia: Pennsylvania 1993, pp 735-765.

18 Pollock LJ, Finkelman I. The digestive apparatus in injuries to the spinal cord and cauda equina. Surg Clin North Am 1954; 34: $259-268$.

19 Arhan P et al. Segmental Colonic Transit Time. Dis Colon Rectum 1981; 24: 625-629.

20 Karasick S, Ehrlich SM. Is constipation a disorder of defecation or impaired motility: Distinction based on defecography and colonic transit studies. Am J Radiology 1996; 166: 63-66.

21 Beuret-Blanquart et al. Colonic transit time and anorectal manometric anomalies in 19 patients with complete transection of the spinal cord. J Auton Nerv Syst 1990; 30: 199-208.

22 Bouchoucha $\mathrm{M}$ et al. What is the meaning of colorectal transit time measurement? Dis Col Rectum 1992; 35: 773 - 782.

23 Kerhavarzian A et al. Delayed colonic transit time in spinal cordinjured patients measured by indium-111 amberlite scintigraphy. Am J Gastroenterol 1995; 90: 1295 - 1300.

24 Madsen JL, Hendel L. Gastrointestinal transit times of radiolabeled meal in progressive systemic sclerosis. Digest Dis Sci 1992; 37: 1404-1408.

25 Menardo G et al. Large bowel transit in paraplegic patients. Dis Colon Rectum 1987; 30: $924-928$. 
26 Metcalf AM et al. Simplified assessment of segmental colonic transit. Gastroenterology 1987; 92: 40-47.

27 Roberts JP et al. Oral (111 In) DTPA scintigraphic assessment of colonic transit in constipated subjects. Digest Dis Sci 1993; 38: $1032-1039$

28 Wald A. Colonic and anorectal motility testing in clinical practice. Am J Gastroenterol 1994; 89: 2109-2115.

29 Rasmussen O, Christiansen J. Physiology and pathophysiology of anal function. Scand J Gastroenterol 31 (Suppl) 1996; 216: $169-174$

30 Stone JM, Wolfe VA, Nino-Murcia M, Perkash I. Colostomy as treatment for complications of spinal cord injury. Arch Phys Med Rehabil 1990; 71: 514-518.

31 Longo W, Ballantyne G, Modlin I. The colon, anorectum, and spinal cord patient. A review of the functional alterations of denervated hindgut. Dis Col Rectum 1989; 32: 261 - 267.

32 Brunton LL. Laxantes. In: Goodman y Gillman, Las Bases Farmacológicas de la Terapéutica, 7a Edición, Editorial Médica Panamericana, 1986; $948-957$.

33 Wrenn K. Fecal impaction. New Engl J Med 1989; 321: 658 - 662.

34 Carone R, Vercelli D, Bertapelle P. Effects of cisapride on anorectal and vesicourethral function in spinal cord injured patients. Paraplegia 1993; 31: 125-127.

35 Cummings JH. Progress report. Laxative abuse. Gut 1974; 15: $758-766$.

36 Chapman RW et al. Effect of oral dioctyl sodium sulfosuccinate on intake-output studies of human small and large intestine. Gastroenterology 1985; 89: 489-493.

37 De Groot GH, De Pagter GF. Effects of Cissapride on Constipation due to a neurological lesion. Paraplegia 1988; 26: $159-161$.
38 Hellström PM, Aly A, Johansson C. Cisapride stimulates small intestinal motility and relieves constipation in mielopathy due to cervical spinal stenosis: case report. Paraplegia 1990; 28: 261 264.

39 Kamm MA. Idiopathic Constipation: Any Movement? Scand J Gastroenterol 27 (Suppl) 1992; 192: 106-109.

40 Martindale W. Part 1: Gastrointestinal Agents. In The Extra Pharmacopeia, 29th edn: The Pharmaceutical Press, 1989, 1078 1107.

41 Micromedex. International Healthcare Series. Drug Evaluation Monographs 1995; Vol 86.

42 Rajendran SK et al. Gastrointestinal transit after spinal cord injury: effect of cisapride. Am J Gastroenterol 1992; 87: 16141617

43 Smith B. Effect of irritant purgatives on the myenteric plexus in man and the mouse. Gut 1968; 9: $139-143$.

44 Fealey RD, Szurszewski JH, Merrit JL, DiMagno EP. Effect of traumatic spinal cord transection on human upper gastrointestinal motility and gastric emptying. Gastroenterology 1984; 87: $69-75$

45 Fenton-Lee D, Yeo BW, Jones RF, Engel S. Colonic volvulus in the spinal cord injured patient. Paraplegia 1993; 31: $393-397$.

46 Binnie NR, Creasey GH, Edmond P, Smith AN. The action of cisapride on the chronic constipation of paraplegia. Paraplegia 1988; 26: $151-158$

47 Etienne M, Verlinden M, Brassinne A. Treatment with cisapride of the gastrointestinal and urological sequelae of spinal cord transection: case report. Paraplegia 1988; 26: $162-164$. 